\title{
DESAFIO HISTÓRICO NA EDUCAÇÃO PRISIONAL BRASILEIRA: RESSIGNIFICANDO A FORMAÇÃO DE PROFESSORES ... UM QUÊ DE UTOPIA?
}

Elenice Maria Cammarosano Onofre Universidade Federal de São Carlos - UFSCar

E-mail: linocam@uol.com.br

\begin{abstract}
RESUMO
As reflexões apresentadas neste artigo são resultado de estudos sobre o papel da escola na prisão e de atividades colaborativas com professores que atuam em unidades prisionais. $\mathrm{O}$ continente latinoamericano apresenta singularidades em relação à questão prisional, e no caso brasileiro, há uma efervescência de ações e de construção de políticas públicas, com o intuito de implementar as Diretrizes Nacionais para a oferta de educação para jovens e adultos em situação de privação de liberdade nos estabelecimentos penais. Entrevistas e conversas informais com professores, observações sistemáticas, estudo de documentos legais, bem como participação em seminários e colóquios nos permitiram rica coleta de material. A análise dos dados evidencia a complexidade do fenômeno educativo e a necessária formação do professor que, para além de conteúdos específicos, deve se apropriar das singularidades do cotidiano e das motivações dos aprisionados, uma vez que constrói com eles um projeto de vida que pode contribuir com a (re)inserção social. Para tanto, há que se investir no fortalecimento e concretização de políticas públicas na perspectiva dos direitos humanos, reforçando propostas presentes no contexto educacional brasileiro de tornar a instituição prisão mais inclusiva e mais humana.

Palavras-chave: História da Educação Prisional; Políticas Públicas; Formação de Professores.
\end{abstract}

\section{HISTORICAL CHALLENGE IN THE BRAZILIAN PRISON EDUCATION: RESIGNIFYING TEACHER EDUCATION... SOMETHING OF AN UTOPY?}

\section{ABSTRACT}

The reflections presented in this article are the result of studies on the role of a prison school and of activities with teachers who act in prison units. Latin America shows singularities in relation to the prison question and, in the Brazilian case, there is an effervescence of actions of public politics with the aim to implement the National Guidelines for the education offered to youths and adults deprived of freedom in penal institutions. Interviews and informal conversations with teachers, systematic observation, study of legal documents, as well as participation in seminaries and debates provided a rich material collection. The data analysis makes evident not only the complexity of the educational phenomenon, but also the need of education for teachers who, besides teaching the specific contents, must make their own the prisoners' everyday singularities and motivations, helping them build a life project that will facilitate their social (re)insertion. So, it is essential to invest in the accomplishment of public politics in the human rights perspective, reinforcing propositions existing in the Brazilian educational context about making prison institutions more inclusive and more human.

Keywords: History of Education in Prison; Public Politics; Teacher Formation. 


\section{Introduzindo o assunto...}

Este artigo apresenta algumas reflexões sobre um momento histórico da educação brasileira - o da aprovação das Diretrizes Nacionais para a oferta de educação para jovens e adultos em situação de privação de liberdade nos estabelecimentos penais, ocorrida em maio de 2010, e os desafios para a sua implementação.

Considerando que uma experiência pedagógica é uma proposta que foge ao estabelecido, que busca novos rumos e é, antes de mais nada, um ato político que procura melhorar algum aspecto do ensino, implementar diretrizes requer um esforço de órgãos públicos em diferentes esferas, da sociedade civil, das universidades e de todos os envolvidos com a educação nesse contexto singular que é o espaço prisional.

Nesse espaço, encontram-se duas lógicas opostas do que significa o processo de reabilitação, ou seja, o princípio fundamental da educação que é por essência transformador, aponta o tempo-espaço da vivência na prisão como possibilidade, enquanto a cultura prisional, caracterizada pela repressão, pela ordem e disciplina, visa adaptar o indivíduo ao cárcere e aponta para um tempo-espaço que determina mecanicamente as ações dos indivíduos. Olhando-se por esse ângulo, estamos diante de uma situação paradoxal, fazendo-se necessária a compatibilização da lógica da segurança com a lógica da educação em um foco de convergência, com o objetivo comum de recuperar o aprisionado, devolvendo-o à sociedade com um projeto de vida adequado à convivência social.

Os privados de liberdade, embora suspensos por tempo determinado do direito de ir e vir, tem garantidos por lei, os seus demais direitos, é a educação é um deles.

Conforme explicita o Parecer CNE/CEB n 4/2010,

Compreendendo a educação como um dos únicos processos capazes de transformar o potencial das pessoas em competências, capacidades e habilidades, e o educar como ato de criar espaços para que o educando, situado organicamente no mundo, empreenda a construção do seu ser em termos individuais e sociais, o espaço carcerário deve ser entendido como um espaço educativo, um ambiente socioeducativo. Assim sendo, todos que atuam nessas unidades - dirigentes, técnicos e agentes - são educadores e devem estar orientados nessa condição. Todos os recursos e esforços devem convergir, com objetividade e celeridade, para o trabalho educativo. (p.14).

O que assistimos nesse momento, é uma efervescência de ações de diferentes segmentos da sociedade, de órgãos da esfera federal e estadual, de entidades envolvidas na implementação das Diretrizes Nacionais, num esforço de elaborar políticas públicas que atendam às demandas por elas estabelecidas.

Para fins deste texto, procurou-se elaborar algumas construções que nos permitissem avançar em uma questão central no processo de implementação das DNs: qual deve ser o perfil do professor para atuar na escola da prisão?

Tomaram-se, como referências teóricas iniciais, dois marcos de estudos de relevância na América Latina: o relatório da Conferência Internacional de Desempenho dos Professores na América Latina, intitulado Formação de Professores na América Latina e Caribe: a busca por inovação e eficiência (REGO \& MELLO, 2002) e o Mapa Regional Latino americano sobre educação em prisões (HANGEL, 2009).

Contextualizar o Brasil na perspectiva da América Latina significa assumir nossas origens históricas e culturais, enraizando grande parte dos problemas que vivemos no presente, em um período de colonização, quer sob hegemonia européia ou norte-americana. 
No continente latinoamericano, heterogêneo e contraditório, se entrelaçam diferentes modos de vida e trabalho, diferentes formas de sociabilidade e jogos de forças sociais, o que também constitui um cenário de semelhanças, convergências e contemporaneidades.

$\mathrm{Na}$ perspectiva de Ianni (1993), para se pensar a América Latina, é preciso compreender a forma como ela se organiza, se desenvolve, rompe e recria. Há realizações e impasses, condições e possibilidades, frustrações e ilusões que marcam e demarcam a história e o pensamento latinoamericano que vive, portanto, na constante busca de uma visão sobre si mesma.

Além disso, hoje, a América Latina está espalhada pelo mundo, e nas palavras de Canclini (2008, p 19), "a América Latina não está completa na América Latina. Sua imagem é formada de espelhos disseminados no arquipélago das migrações."

Nesse sentido, ao pensarmos o temário formação de professores para as escolas das prisões, parece-nos importante partir do estudo desses documentos, tomando a perspectiva de América Latina, pois se evidencia uma realidade que permeia o continente e vai para além dele, não constituindo, portanto, uma singularidade brasileira.

Não temos a intenção de apresentar uma análise desses documentos, mas formalizar os que subsidiaram e embasaram as reflexões para a elaboração deste texto.

\section{Compondo o cenário...}

O Mapa Regional Latinoamericano sobre educação em prisões apresenta uma análise da situação prisional, trazendo elementos de reflexão sobre a especificidade da temática, bem como reitera o compromisso que o Brasil deve assumir, neste momento da implantação das Diretrizes Nacionais para a oferta de educação nos estabelecimentos penais. Para Rangel (2009), as prisões são espaços complexos onde se concentram todas as dificuldades da sociedade em matéria de educação - fracasso escolar, analfabetismo, gestão da diversidade, exclusão social, etc. Nesse sentido, se constitui verdadeiro desafio e compromisso governamental convertê-las em espaços educativos.

No Prólogo do Mapa Regional, o pesquisador Marc de Maeyer, interroga: Por que a educação em prisões esteve tanto tempo ausente dos programas de governo na América Latina? E o autor anuncia:

A opinião pública não suportaria que fosse dada maior atenção aos culpados do que às vítimas, e os gestores das prisões, na maioria das vezes superlotadas, apresentam outras urgências a dar conta: segurança, controle do tráfico, garantia das necessidades básicas como alimentação, higiene e saúde. (MAEYER, 2009, p. 12).

Para o autor, a educação nas prisões surgiu no plano das preocupações há muito pouco tempo, e passamos da ignorância sobre a problemática para uma expectativa por vezes exagerada: redução da pena pela freqüência à escola, reeducação para reabilitação, preparo para a vida em liberdade, ensino da leitura e escrita, aprendizagem de um ofício e, supostamente, que o aprisionado "aprenda a aceitar" as regras sociais.

Mayer (2009) pondera, no entanto, que a educação não é uma mercadoria nem um produto, mas um processo que deve ser concebido e vivido pelo conjunto de atores que vivenciam esse cotidiano. "É necessário transformar a prisão em um espaço educativo e não transformar o aprisionado em receptor de sequências educativas." (MAYER, 2009, p. 14).

Nessa direção,

Educar é depositar em cada homem toda a obra humana que lhe antecedeu: é fazer de cada homem o resumo do mundo vivente, até o dia 
em que ele vive: é pô-lo em nível de seu tempo para que flutue sobre ele e não deixá-lo debaixo de seu tempo, com o que não poderá sair a flutuar; é preparar o homem para a vida. (MARTÍ, 2007, p. 81)

Aprender ao longo da vida implica, para Mayer (2009), sair do status provisório de aprisionado e inscrever-se em uma perspectiva de educar-se em longo prazo. Nessa perspectiva, ser educador em prisões é trabalhar com a diversidade, a diferença, o medo, é enfrentar as situações tensas do mundo do crime e apostar no ser humano. Isso exige do educador aprendizagens de outra natureza, que não somente as oferecidas em salas de aula da universidade.

O relatório da Conferência Internacional de Desempenho dos Professores na América Latina, apresenta que o tema formação de professores vem alcançando destaque, neste inicio do século XXI, entre pesquisadores e acadêmicos, como também entre aqueles que se responsabilizam pela definição de políticas que afetam seus sistemas de profissionalização. Todos os que trabalham na área de formação de professores parecem estar convencidos de que as reformas que visam à melhoria da educação básica terão sustentação somente se existirem professores preparados e comprometidos com a aprendizagem dos alunos.

Os desafios da sociedade da informação colocam em xeque os modelos escolares tradicionais, assim como os de desempenho docente e de eficiência das instituições formadoras. Como sinalizam Brzenzinski (2000), Hargreaves et al. (2002) e Morin (2000), surge um outro perfil que a escola e os professores devem assumir para atender às demandas do mundo contemporâneo e, neste novo contexto, marcado pela modernização, pelo fortalecimento dos direitos da cidadania e pela disseminação das tecnologias da informação, a educação passa a ter papel mais amplo e complexo.

Nessa direção, tem havido questionamento intenso - social e acadêmico - em torno do papel da educação, da escola e dos professores na construção da sociedade, e isto sugere, no dizer de Alarcão (2001), uma espécie de reinvenção da profissão docente, onde as expectativas depositadas no professor são diferentes daquelas que vigoravam num passado recente. Há que se pensar em um profissional acolhedor da diversidade, aberto à inovação, comprometido com o sucesso da aprendizagem e solidário com as características e dificuldades de seus alunos. Para tanto, é importante que esse profissional tenha capacidade de articular conteúdos curriculares a conhecimentos pedagógicos, que garanta a efetivação de projetos interdisciplinares, trabalhe em equipe e de maneira reflexiva, improvise com criatividade e assuma com autonomia a gestão de seu desenvolvimento profissional. (REGO \& MELLO, 2002).

O professor passa a ser entendido como um profissional preparado para examinar com criticidade a sua prática e o contexto em que trabalha, assim como para lidar de modo autônomo com as incertezas e problemas do cotidiano escolar, investigando sua sala de aula e a cultura institucional, sendo, portanto, um produtor de conhecimentos.

Ao encontro dessa proposta, Rego \& Mello (2002) apontam alguns desafios para a melhoria da qualidade da formação de professores na América Latina, pois para as autoras,

Uma boa docência requer bons mestres que, por sua vez, requerem boa formação, boa direção e boa remuneração. Sem dúvida, os docentes latinoamericanos tendem a estar mal capacitados, mal dirigidos e inadequadamente remunerados, por isso é difícil chegar a bons resultados. (p. 6) 
Há que se assinalar também, que a participação dos professores na definição das políticas educacionais tem sido limitada, e esse fator prejudica a concretização das mudanças desejadas.

Muitos docentes, por não serem convidados a se envolverem como coautores das reformas pretendidas, colocam-se no papel de meros executores dos programas definidos em instâncias superiores. Nessa perspectiva, não se apropriam dos princípios das reformas propostas e, principalmente, não se sentem devidamente estimulados a realizar alterações na sua prática pedagógica. (REGO \& MELLO, 2002, p. 7).

O trabalho diagnóstico de Krawczyk, Campos e Haddad (2000) sobre os avanços conseguidos nos sistemas latinoamericanos, de um modo geral, constata a presença de problemas relacionados à formação e ao desempenho dos docentes como: a frequente desvinculação dos programas de formação inicial, continuada com as exigências das escolas na sociedade contemporânea, a significativa deterioração das condições de trabalho, o desprestígio social da profissão, a desmotivação dos professores e a escassa participação na gestão do processo educativo.

Pode-se inferir, com base nos dados apresentados por Rego \& Mello (2002), que o exame da realidade latinoamericana mostra que os problemas relacionados à formação e desempenho dos professores persistem e demandam investimentos de diferentes esferas de ação. As autoras sinalizam que alguns avanços têm sido empreendidos no sentido de se acelerar melhorias da qualidade e da equidade em educação, o que nos permite vislumbrar possíveis paradigmas de construção de políticas públicas com vistas a profissionalizar o trabalho docente como condição básica para que se possa oferecer uma educação de qualidade, independente do espaço em que se encontre.

Nessa perspectiva, apontamos o espaço a que nos remete à construção deste texto e às lentes através das quais temos focado nossos estudos - um campo educativo que não pode continuar à margem nas discussões relativas à construção de políticas públicas: a escola das prisões e os profissionais que nela atuam.

$\mathrm{Na}$ construção dessas reflexões, tomou-se como material empírico, recortes de dados de pesquisa coletados em investigações anteriores sobre o papel da escola na prisão e que têm sido aprofundadas em desdobramentos de estudos, bem como em conversas informais e observações sistemáticas, registradas em diários de campo, a partir de experiências pedagógicas com educadores prisionais. Ao longo do período transcorrido entre os anos 2006 e 2011, a inserção em escolas de unidades prisionais do estado de São Paulo e de outros estados brasileiros, em atividades colaborativas com grupos de professores iniciantes e experientes, tem sido conduzida pela seguinte questão norteadora: como os professores lidam com as contingências do espaço e efetivamente são preparados para assumir as salas de aula da prisão?

Sem a pretensão de formular respostas às inquietações que permeiam a formação de professores para atuarem nas escolas das unidades prisionais brasileiras, com base nas determinações postas pelas Diretrizes Nacionais para a oferta de educação nos estabelecimentos penais, este texto pretende agregar às discussões em torno dos modos de conceber a formação docente, alguns elementos que possam contribuir com o necessário investimento em políticas públicas focadas neste segmento específico da educação escolar.

\section{Apresentando o palco...}

Pensar a educação em espaços de privação de liberdade, especialmente em prisões, se reveste de discussões por vezes calorosas, entre acadêmicos, autoridades do campo 
educacional, instituições e responsáveis vinculados ao sistema prisional, sociedade, Organizações Não Governamentais, a mídia em geral, tendo em vista os diferentes olhares que são dirigidos a homens e mulheres aprisionados.

Questões recorrentes em torno da educação em prisões são: para quê educação em prisões? A quem a educação serve? Se não temos educação com qualidade para nossas crianças para que investir na educação de criminosos? Se as escolas de ensino público carecem de recursos e materiais de diferentes naturezas para que dotar escolas de prisões com tais recursos? Se não temos formação inicial e continuada de professores que atuam em escolas públicas, para que investir na formação de educadores para criminosos?

Ao lado dessas questões, ainda nos deparamos com algumas de outra natureza: se o objetivo da prisão é punir e ali temos um ambiente que preza pela repressão e submissão aos ditames da organização, como pensar em educação se esta se caracteriza como possibilidade de transformação e emancipação dos indivíduos? Para que serve a escola na prisão? Qual o papel dos professores nesse contexto em que tudo se vigia e se controla? O que eles podem e devem ensinar?

As questões anteriormente anunciadas têm sido discutidas por estudiosos do tema em diferentes áreas: na educação, na sociologia, na psicologia, no direito, entre outras.

Os recortes que estabelecemos para este texto, vinculados aos estudos que temos desenvolvido, ancoram-se em pesquisadores que defendem a educação como prática social relevante nas escolas dos espaços prisionais, como os de Silva (2001), Onofre (2002), Leme (2002), Penna (2003), Vieira (2008), Serrado Júnior (2009), Julião (2009), Lourenço (2011), entre outros, pois evidenciam que a escola na prisão, assim como as demais práticas sociais ali existentes, é geradora de interações entre os indivíduos, promove situações de vida com melhor qualidade, enraíza, recompõe identidades, valoriza culturas marginalizadas, promove redes afetivas e permite (re)conquistar cidadania. Inserida em um espaço repressivo, ela potencializa processos educativos para além da educação escolar, evidenciando-se a figura do professor como ator importante na construção de espaços onde o aprisionado pode (re) significar o mundo como algo dinâmico e inacabado.

Apesar das tensões resultantes de posições antagônicas em relação ao papel da escola nas unidades prisionais, há uma convergência em relação ao papel determinante, embora não exclusivo, que ocupa o professor no sentido de se promover uma educação com qualidade, independente do espaço em que esteja inserida. Pensar, portanto, na implementação de políticas públicas que visam a qualidade e equidade no campo educacional, não podem deixar de privilegiar questões relativas à formação docente.

Sendo o professor elemento chave da mudança educativa,

ainda que não se pretenda atribuir aos professores toda a responsabilidade pelo êxito das reformulações dos sistemas educacionais, todos partilham do pressuposto de que mudanças qualitativas dependem também do envolvimento do professorado e da transformação dos modelos formativos existentes. (REGO \& MELLO, 2002, p. 10).

No entanto, temos assistido a avanços pouco significativos e recomendações frágeis sobre a necessidade de reformulação dos modelos formativos vigentes e do perfil desejável para o professor. Tal situação caracteriza a formação de professores que atuam em diferentes níveis do ensino e em diferentes espaços educativos e, no caso das escolas das prisões, é agravada pelas circunstâncias e peculiaridades do sistema prisional.

A existência de uma cultura própria da prisão torna a escola singular, e o seu cotidiano nem sempre permite apreender os significados vividos naquele espaço-tempo. $\mathrm{O}$ 
desafio posto é como se inserir nesse mundo, sem abdicar de seus elementos culturais próprios, sem perder fios da tessitura da trama que revela a sua essência. As práticas sociais vivenciadas na escola podem desvelar outras possibilidades do fazer escolar, cabendo ao professor promover práticas anunciadoras de novas possibilidades de humanização e produção de subjetividades. (STRECK; ADAMS; MORETTI, 2010).

Dadas as características da prisão e a situação social dos sujeitos que nela vivem, torna-se, portanto, imprescindível, a compreensão do espaço onde a escola está inserida, a fim de estabelecer uma estratégia educativa que contemple a complexidade e a singularidade da instituição. A "sociedade dos cativos" se organiza em função de regras e códigos, o que nos leva a supor que estes produzem nos indivíduos efeitos em sua convivência diária, nas concepções sobre a realidade e em sua própria situação no âmbito da escola. A escola, mesmo inserida na prisão, é considerada uma instituição com responsabilidades específicas, que se distingue de outras instâncias de socialização e tem identidade própria e relativa autonomia.

Nessa perspectiva, PÉREZ GÓMEZ (1995) concebe o papel da escola como o de um "espaço ecológico de cruzamento de culturas": a cultura escolar, a experiencial e a cultura social. Os professores chegam influenciados pela cultura acadêmica e, ao confrontá-la com a cultura escolar e experiencial, sofrem, na maioria dos casos, um "choque de realidade" (VEENMAN, 1988). Para compreender e enfrentar esse cruzamento de culturas, o professor necessita não apenas de reflexão pessoal, mas também do apoio dos mais experientes, com quem possa compartilhar seus estranhamentos, angústias e problemas, em busca da construção de sua identidade docente.

De acordo com Veenman (1988), o "choque de realidade" indica o corte que se dá entre os ideais criados durante a formação inicial e a realidade do dia-a-dia numa sala de aula, ficando claro, portanto, que a entrada na carreira docente é brusca e repentina, tendo o professor iniciante, que desempenhar tarefas e funções de um professor experiente. Esse período da docência se qualifica, para Guimarães (2004), como um período de vulnerabilidade, pois é marcado por insegurança, angústia e medo, podendo "atingir mais ou menos o professor, ser mais ou menos perturbador, consoante as características pessoais e o contexto em que está inserido" (p.482).

A passagem de aluno a professor assemelha-se ao que White (1989) chama de "ritual de iniciação". Esse ritual de passagem para um novo grupo socioprofissional nem sempre ocorre sem sobressaltos e, muitas vezes, há cortes bruscos que afetam o jovem professor. Para se adaptar à nova situação, o seu modo de pensar e agir passarão a ser, mais ou menos, condicionados pelos modos de pensar e agir dos outros membros do grupo a que passa a pertencer. É um novo estatuto que adquire, com direitos e obrigações e, para sobreviver a essa crise de identidade, sente necessidade de pautar o seu comportamento, a sua aparência, o seu discurso, pelas normas vigentes na instituição da qual passou a fazer parte.

Tomando como referência o espaço prisional, é importante considerar que os professores passam por processo semelhante à chegada do novato na prisão, quando the são passadas as "regras da casa" pela equipe dirigente, no processo denominado "boasvindas". Trata-se de um momento em que avalia sua condição de duplamente iniciante: como professor em um espaço com características próprias e onde rapidamente deve aprender a sobreviver - ali ele percebe a importância de buscar saberes, não só para lidar com diferentes culturas, mas para lidar com conflitos e dilemas para os quais não foi preparado na formação inicial e nem em experiências em outros espaços escolares.

A gestão dos dilemas é difícil para o professor que entra em um mundo diferente, que dele espera que seja responsável e tome decisões acertadas, tendo de "escolher entre o 
que deve ser, o que se espera que faça e o que as circunstâncias obrigam que se faça." (SILVA, 1997, p. 58). A fala que segue, de um professor iniciante, evidencia tais dilemas: Aqui tem regras para tudo, e a gente tem que aprender rápido para não afundar. As saídas temos que encontrar depressa... Sabedoria na prisão é saber conviver com as circunstâncias, aprender a ouvir e a falar pouco.

Uma das condições básicas para enfrentar o "choque de realidade" é a imagem que o professor tem de si mesmo como agente de transformação dessa realidade, pois isso pode garantir, em parte, sua permanência no espaço prisional. $\mathrm{O}$ mal-estar docente que essa chegada pode lhe representar, aliado a horários pouco estimulantes das aulas, o comprometimento dos dias letivos pelas interferências do sistema prisional, a evasão escolar, os baixos salários acabam sendo compensados, no dizer dos professores experientes e iniciantes, em fonte de bem-estar docente, pelo reconhecimento de seu valor para os alunos, o respeito e a confiança na figura do professor, despertando motivações intrínsecas pertinentes à carreira, como o gosto de ser professor e a realização pessoal, diante dos avanços por eles demonstrados. O que vivemos aqui é uma situação desestimuladora, pois nosso trabalho não é valorizado, a escola está lá por determinação da lei. Tudo é motivo pra suspender aulas, e os horários são os mesmos do banho de solquem prefere ir à escola em lugar do banho de sol? Mas, apesar de tudo, eu continuo lá faz muito tempo... fico realizado quando conseguem escrever sozinhos um bilhete... eles gostam de aprender o que tem relação com os lugares onde viveram, gostam de contar e prestam muita atenção... O aprendizado aqui tem que ter utilidade para eles...

Diante desse contexto, cabe assinalar a ausência da formação acadêmica específica para professores que desenvolvem atividades em escolas das prisões. Há algumas iniciativas tímidas na formação de educadores para atuarem em Educação de Jovens e Adultos, embora o temário educação prisional, seja assunto fora de pauta nesses cursos. $\mathrm{O}$ cenário da prisão é singular, apresenta necessidades advindas da trajetória escolar, história social e cultural, de questões vinculadas à violência e ao delito - esse contexto tem, portanto, especificidades que evidenciam a complexidade do ato pedagógico, o que justifica a importância da formação, uma vez que o espaço já é fator determinante de insegurança, quer para iniciantes ou experientes.

Um fator recorrente e apontado na formação é que na maioria dos cursos de licenciatura há uma ênfase nos conhecimentos do mundo acadêmico e teórico, normalmente desarticulados entre si e, às vezes, pouco significativos com as variáveis que se entrelaçam nas situações cotidianas de ensino e aprendizagem. Por seu lado, a prática deve ser uma fonte relevante de conteúdos para a formação, mas, frequentemente, o contato com a prática se dá por meio de estágios pouco produtivos, quase sempre realizados no final dos cursos. Cabe ao futuro professor a tarefa de integrar e transpor sozinho o que aprendeu na esfera do saber para a esfera do saber fazer. (REGO \& MELLO, 2002).

As autoras assinalam também a necessidade de se repensar a formação dos formadores, uma vez que há poucas experiências que integram, num mesmo universo conceitual e prático, o projeto pedagógico da instituição de formação e o projeto pedagógico das escolas no campo da prática. De igual forma, a articulação entre formação inicial e em serviço é uma tradição quase inexistente, uma vez que a formação em serviço não pergunta o que e como o professor aprendeu em sua formação inicial, e esta não considera a continuidade do processo constitutivo do docente.

O que temos assistido diante dessa realidade é que os professores que optam por iniciar ou continuar sua carreira em espaços prisionais, embora se sintam despreparados, mostram uma condição que é universal a todos os que realizam tarefas pedagógicas: a 
sensibilidade pelos problemas sociais que promovem mecanismos de exclusão social, (SCARFÒ, 2002), pautando sua prática pedagógica na instauração do diálogo e na construção de relações de proximidade no sentido do acolhimento.

Diante dos questionamentos em relação ao perfil do professor para atuar nos espaços prisionais e sua formação, algumas questões são postas: se ali temos uma escola como as demais, para que um professor com perfil diferenciado? Que estratégias metodológicas devem ser usadas?

Nessa direção, algumas considerações merecem destaque. Por se tratar de um espaço singular, regido por normas e regras específicas e que privilegiam a manutenção da ordem estabelecida pelo sistema prisional, o professor deve se apropriar desses saberes (que não são discutidos em sua formação inicial), fazendo-se necessário um processo de ambientação, conforme estabelecem as Diretrizes Nacionais.

Muitos profissionais contratados, nem mesmo possuem experiências com o trabalho docente, com jovens e adultos. Saíram das universidades para atuar em escolas regulares do mundo livre, sem nem mesmo terem vivenciado qualquer iniciativa e/ou experiência com a Pedagogia Social. Poucas são as universidades que investem em uma matriz curricular que estimule e possibilite o discente de visualizar alternativas no campo profissional da educação além dos postos cotidianamente dispostos no mercado de trabalho. (BRASIL, 2010, p. 21)

Diante desse contexto, cabe aos professores experientes e à equipe multidisciplinar que atende os indivíduos em privação de liberdade, promover situações que aproximem os iniciantes das "regras da casa" e dos limites e possibilidades para desenvolver as ações educativas na sala de aula.

Como sinaliza Scarfò (2002), o professor ali se reveste como um profissional que transmite conhecimentos específicos, mas também contribui com a elaboração de um projeto de vida que se constrói pelo diálogo, pela sensibilidade aos problemas sociais, pela disponibilidade para a escuta. Em relação às estratégias metodológicas, estas estão vinculadas às da educação de jovens e adultos, respeitando seus saberes da vida, expectativas, visões de mundo, mas há que se respeitar as regras específicas do contexto, ou seja, recursos que possam trazer qualquer tipo de risco em relação à segurança, não são permitidos. Dessa forma, todo o material é examinado pelo setor de segurança, antes de sua utilização.

Em muitos casos, as atividades realizadas pelas escolas são desqualificadas e ameaçadas, dependendo quase que cotidianamente de consentimentos. [...]. O excesso de zelo pela segurança geralmente impede qualquer criatividade docente: passar filmes, convidar palestrantes, desenvolver pesquisas, atividades coletivas, em muitos estabelecimentos penais são atividades quase impossíveis. (BRASIL, 2010, p. 21)

Pensar a escola em comunidades excluídas e pobres também nos remete a uma reflexão relevante - o valor da educação, e o prestígio de quem a ministra é grande. Nessa perspectiva, para os privados de liberdade, aprender a ler e escrever (mesmo que bilhetes) significa libertar-se da dependência do colega de cela que assume o papel de escriba e conhecedor de uma intimidade familiar que por vezes, fragiliza o indivíduo. Tal situação significa "dívida" ao colega de cela, e na prisão, dívida significa submissão e risco. O valor dado ao professor pelo aluno é significativo, pois além dos ensinamentos dos conteúdos 
escolares, ele significa a oportunidade do contato com alguém fora dos muros - é o elo perdido com a família e a sociedade através do isolamento e afastamento do convívio social.

A reflexão sobre o papel do profissional que assume as salas de aula nos leva a desafios no sentido de equacionar problemas que também existem "fora dos muros" baixa remuneração e precariedade das condições de trabalho. Além da precariedade das políticas salariais e de incentivo no plano de carreira, os profissionais são obrigados a exercer suas atividades em condições inadequadas, uma vez que muitas escolas são desprovidas de recursos materiais e humanos.

A própria arquitetura prisional geralmente não prevê espaço para o desenvolvimento de atividades educativas, e no caso das escolas,

Enquanto atualmente se discute a necessidade de criação de espaços para atividades laborais no cárcere, espaços para a educação, artes e esporte não são considerados artigos de primeira necessidade, são, em geral, totalmente desconsiderados em uma política de execução penal, literalmente colocados em segundo plano. (BRASIL, 2010, p. 17)

Reconhecer o papel relevante dos professores no processo educativo tem sido um discurso desgastado, tendo em vista os investimentos efetivamente destinados à sua formação, atuação e profissionalização. Não há formação de excelência que sobreviva ao desprestígio e desvalorização do trabalho docente - trata-se de ressignificar o que é valorização no novo contexto, e no caso das prisões, a aprovação das Diretrizes Nacionais, embora tenha significado um marco na história da educação prisional, sua implementação será efetivada através de políticas publicas que atendam às demandas anteriormente assinaladas (formação, ambientação, valorização salarial e profissional, condições objetivas e subjetivas de trabalho).

Buscar novos contornos para a formação implica no dizer de Rego \& Mello (2002), a necessidade de coerência entre o modelo de formação e o de exercício, enfatizando que as práticas de formação centrem atenção no perfil do professor, necessário às demandas do momento e do contexto, que tenha condições para tomar decisões com autonomia e competência, no sentido de promover a transposição didática do objeto de ensino para o contexto de aprendizagem, tomando como ponto de partida o que o aluno já aprendeu e como aprendeu, assim como os conteúdos que precisam ser ressignificados para ganharem sentido e significado no momento presente e no futuro.

Para o homem em privação de liberdade, a relação presente-passado-futuro é fundamental, em qualquer programa educativo que se lhe apresente. É o cotidiano que revela as bases sobre o que é possível, mas não deixa de trazer embutido o passado, enquanto memória e incorporação de vivências. Sua expectativa de futuro é algo que deve ser também considerada, e a educação pode oferecer condições para que ele possa conviver, no presente, com diferentes circunstâncias, sabendo a hora de "mostrar-se" ou "esconder-se", de falar ou de calar, de proteger-se para sobreviver. O indivíduo em privação de liberdade traz, por outro lado, enquanto memória, vivências por vezes negativas, de situações pelas quais passou antes e durante sua carreira delinquencial. Em suas expectativas de futuro estão o desejo de começar uma nova vida, na qual possa trabalhar, voltar a estudar e construir uma família. Embora os estudos sobre a reincidência criminal apontem que suas expectativas acabam, na maioria das vezes, frustradas pelos rótulos, pelo despreparo em assumir atividades profissionais, por distorções de visão de mundo que fatalmente adquirem na "sociedade dos cativos" (SYKES, 1999), é necessário 
que sejam dados alguns passos na busca da construção de projetos educativos que visem à melhoria das condições de vida nas unidades prisionais.

Analisando o significado e sentido da vida nos espaços de privação de liberdade, Onofre $(2002 ; 2011)$ sinaliza alguns pontos que devem estar presentes quando se pensa o processo educativo, considerando esse momento da história de vida do aprisionado. Ao chegar à prisão, o sentenciado traz uma concepção de si mesmo formada ao longo de sua vivência no mundo doméstico. Nesse momento, ele é despido de seu referencial, e o processo de admissão o leva a outras perdas significativas em relação ao seu pertencimento à sociedade. As despir sua roupa e vestir o uniforme da instituição, o indivíduo começa a perder suas identificações anteriores para sujeitar-se aos parâmetros ditados pelas regras institucionais.

Para a autora, o processo de "desterritorialização" e "reterritorialização" (e) que mostra a trajetória dos indivíduos desde o abandono da sociedade em que viviam até sua inscrição em um microcosmos no qual se destrói o essencial de suas existências, deixa clara a construção dessa experiência do aprisionado. $O$ encarceramento vai trazer ao indivíduo situações novas às quais precisa se adaptar para sobreviver. Tais situações não dizem respeito somente à dominação do sistema, mas ao convívio com os companheiros, ao convívio cotidiano que ele precisa descobrir.

\section{Entre desafios e tarefas...}

Tomando-se com ângulo de reflexão as considerações apresentadas neste texto, pensar a formação de professores que atuam nas escolas das prisões, nos leva a algumas ponderações: em que momento da história da educação brasileira foi avaliada a formação necessária para atuar nesse contexto? Os cursos de licenciaturas ofereceram e oferecem disciplina/ disciplinas que permitam aos futuros professores alguma aproximação com essa realidade? As escolas das prisões foram em algum momento pensadas como possibilidade de campo de estágios supervisionados? Os professores formadores sabem que existem escolas nas prisões?

Fica evidenciado nas Diretrizes Nacionais para a oferta de educação nas prisões, que esse foco de atenção não aconteceu até o momento, e alguns estados brasileiros têm assumido através da formação continuada, oferecer alguns subsídios para a ambientação e trabalhos integrados com universidades, ONGs e Fundações, no sentido de promover a educação escolar, iniciando com os professores um processo formativo que atenda às demandas ali existentes.

A educação continuada tem privilegiado, de forma geral (também "fora dos muros"), alguns elementos como: reflexões sobre a prática docente entre docentes experientes e iniciantes, cursos de formação continuada (e não momentos pontuais de formação), participação dos professores no desenho das políticas educativas, apropriação da cultura prisional e do cotidiano da instituição, oferta de certificação para progressão de carreira, estimulando o compromisso pessoal com a formação permanente, e que tem se constituído em avanços e experiências exitosas que balizam a melhoria da educação nas prisões.

Com isso, não estamos a afirmar que tais situações sejam em número satisfatório e ocorram com frequência, mas que são possíveis, quando existe vontade e decisão política. Não são hipóteses, mas possibilidades que existem em regiões que se ancoram em políticas de formação docente, independente do espaço onde os professores atuem. 
Para tanto, algumas convergências podem ser propostas em tempos de implementação de Diretrizes Nacionais para a oferta de educação para jovens e adultos nos estabelecimentos prisionais:

- É preciso que a política exista e que haja clareza do papel da escola e do professor nas unidades prisionais;

- As instituições formadoras precisam passar por mudanças em seu interior, garantindo formação de professores para atuarem nas prisões;

- O currículo de formação deve contemplar a formação de professores com aportes teóricos e estágios nas escolas da prisão;

- O professor deve participar como protagonista na construção e implementação das políticas públicas voltadas para a educação escolar em espaços prisionais;

- O contexto prisional deve ser entendido como um lugar onde o professor ensina, mas também aprende;

- Articulação do projeto pedagógico dos cursos de formação com os projetos das escolas das unidades prisionais onde se realiza a prática dos futuros professores;

- Investimento na produção de materiais didáticos que contribuam com o trabalho do professor, respeitando-o como produtor de conhecimentos.

Em boa parte do mundo vem se consolidando a idéia de que a educação superior deve ser requisito para formar os professores, e que a formação para a prática docente integre campos de ciências pedagógicas e sociais, conteúdos e didáticas especiais, bem como as temáticas relativas à realidade escolar. Todavia, o que tem sido registrado são algumas iniciativas empreendidas, mas que deixam transparecer que ainda não se sabe como alcançar esse objetivo. (REGO \& MELLO, 2002).

Tem-se reconhecido que a universidade sozinha não é capaz de dar conta de toda a formação, especialmente no que se refere à dimensão prática. Uma alternativa interessante é que as escolas e salas de aula funcionem como laboratórios para a realização de pesquisas, descobertas e conhecimentos que alimentem a própria prática e o campo das investigações.

O estudo de Hargreaves (1998) indica que não adianta mudar o lócus de formação, se a concepção dessa formação não se reformular, ou seja, qual deve ser o preparo do professor? Para o autor, o ponto de partida das decisões sobre o lugar da formação docente deve ser o perfil de formação desejado para o professor, pois como em qualquer profissão, os saberes teóricos são necessários, mas não suficientes, para garantir as competências que a contemporaneidade exige. É crucial, portanto, que se discuta o perfil desejável para o professor em função das novas demandas e das que estão por vir.

Partindo da perspectiva assinalada por Gadotti (2003, p. 137), "que a formação do educador deve ser contínua, sistematizada e baseada na prática" e por Freire (1993), que é ensinando que se aprende, pode-se inferir com segurança que é a prática docente que nutre o conhecimento do ensino na prisão.

Pensar a educação na escola da prisão requer, por seu lado, tomar a perspectiva desse espaço, regido por normas e regras onde predomina a garantia da segurança, como definidor de práticas que ali podem acontecer, contando-se com boa dose de cautela, pois nem sempre as experiências podem ser transplantadas de uma realidade para a outra.

Ainda que o direito à educação seja garantido, a todos os cidadãos, independente do espaço em que estão inseridos, e o indivíduo em situação de privação de liberdade tenha 
esse direito garantido, o sistema educacional deve ser pensado em sua especificidade, bem como a formação dos professores.

Construir um projeto de vida que leve a alguma possibilidade de sucesso para quando adquirir liberdade - visto o estigma que segrega o indivíduo que passou pela prisão, e que muito contribui para a reincidência - trata-se de um processo educativo que vai muito além da sala de aula e dos conteúdos escolares.

\begin{abstract}
A educação na prisão, não é apenas ensino, mesmo que devamos ter certeza de que a aprendizagem de conhecimentos básicos esteja assegurada. (...) a educação deve ser, sobretudo desconstrução/reconstrução de ações e comportamentos (MAEYER, 2006, p. 22).
\end{abstract}

O que se pretendeu nestas reflexões foi apontar pontos nevrálgicos da formação de professores, uma vez que estamos vivendo um momento da história da educação prisional significativo, com demandas postas aos estados, no sentido de garantir educação com qualidade nas escolas. Há que se enfatizar, no entanto, que a aprovação das Diretrizes Nacionais, embora tenha significado um avanço, alcançado por lutas desde 1980, trata-se de um marco histórico relevante, mas não há garantias de que sejam efetivamente implementadas, uma vez que dependem de estudos, análises, reformulação nos padrões de educação escolar que acontece na maioria dos espaços prisionais - físicos e humanos, decisões coletivas que reconheçam a relevância não só de assegurar a implementação, mas transformar o cenário educativo existente, fora e dentro das prisões.

Os responsáveis pela reformulação de políticas educacionais, os organismos financiadores, as universidades e outras instituições devem promover investimentos nesse setor, buscando garantir mecanismos de implementação das Diretrizes Nacionais. As questões colocadas a partir dos novos contextos da realidade estão sendo ressignificadas e reformuladas, e dizem respeito a um processo vivido pelo conjunto de pessoas e estruturas de mediação, na perspectiva de construção de um projeto educativo emancipatório. A incidência de políticas públicas é uma opção ética, de afirmação de ideais e posições frente a um contexto injusto e desigual, devendo, portanto, desenvolver-se em ao menos quatro âmbitos de espacialidade: local, regional, nacional e internacional. Tem como horizonte a sociedade civil, garantindo sua participação com formas e estratégias próprias.

Se é assim, temos tarefas na agenda imediata dos países latinoamericanos, de acordo com tempos e momentos, que em pouco diferem, quais sejam as de reforçar a concepção, tanto nos setores estatais como na própria sociedade, de que a educação é um investimento e não um gasto, diretamente relacionado com o desenvolvimento humano dos setores que sofrem marginalização, exploração e exclusão.

\title{
Referências:
}

ALARCÃO, I. (Org.). Escola reflexiva e nova racionalidade. Porto Alegre: Artmed, 2001.

BRASIL. Parecer CNE/CEB No 4/2010. Diretrizes Nacionais para a oferta de educação de jovens e adultos em situação de privação de liberdade nos estabelecimentos penais. Brasília, DF: MEC/CNE/SECAD, 2010.

BRZEZINSKI, I. Pedagogia, pedagogos e formação de professores. Busca e movimento. Campinas: Papirus, 2000. 
CANCLINI, N. G. Latinoamericanos buscando lugar en este siglo. Buenos Aires: Paidós, 2008.

FREIRE, P. Educação como prática da liberdade. Rio de Janeiro: Paz e Terra, 1983.

GADOTTI, M. Perspectivas actuales de la educación. México: Siglo XXI, 2003.

GUIMARÃES, M. de F. O desenvolvimento de uma professora de matemática do ensino básico: uma história de vida. Tese (Doutorado em Educação) - Faculdade de Ciências da Universidade de Lisboa, Porto, 2004.

HARGREAVES, A. Profesorado, cultura y postmodernidad: cambian los tempos, cambia el profesorado. Madrid: Morata, 1998.

HARGREAVES, A. et al. Aprendendo a mudar: o ensino para além dos conteúdos e da padronização. Porto Alegre: Artmed, 2002.

IANNI, O. O labirinto latino-americano. Petrópolis: Cortez, 1993.

JULIÃO, E. F. A ressocialização através do estudo e do trabalho no sistema penitenciário brasileiro. 2009. Tese (Doutorado em Ciências Sociais) - Universidade Estadual do Rio de Janeiro, Rio de Janeiro, 2009.

KRAWCZYK, N.; CAMPOS, M. M.; HADDAD, S. (Orgs.). O cenário educacional latino-americano no limiar do século XXI: reformas em debate. Campinas: Autores Associaods, 2000.

LEME, J. A. G. A cela de aula: tirando a pena com letras. Uma reflexão sobre o sentido da educação nos presídios. 2002. Dissertação (Mestrado em Educação). Pontifícia Universidade Católica de São Paulo, São Paulo. 2002.

LOURENÇO, A. da S. O espaço de vida do agente segurança penitenciária no cárcere: entre gaiolas, ratoeiras e aquários. Curitiba: Juruá, 2011.

MAEYER, M. de. Prólogo. In: RANGEL, H. (Coord.). Mapa Regional latinoamericano sobre educación en prisiones. Notas para el análisis de la situación y la problemática regional. Centre International d'études pédagogiques (CIEP), 2009.

Na prisão existe a perspectiva da educação ao longo da vida? Alfabetização e Cidadania. Revista de Educação de jovens e adultos. Brasília: RAAB/UNESCO/Governo Japonês, 2006.

MARTÍ, J. Educação em nossa América. Ijuí: Unijuí, 2007.

MORIN, E. Os sete saberes necessários á educação do futuro. São Paulo: Cortez; Brasília, DF: UNESCO, 2000.

ONOFRE, E. M. C. Educação escolar na prisão. Para além das grades: a essência da escola e a possibilidade de resgate da identidade do homem aprisionado. 2002. Tese (Doutorado em Educação) - Universidade Estadual Paulista, Araraquara, 2002.

Educação escolar na prisão: controvérsias e caminhos de enfrentamento e superação da cilada. In: LOURENÇO, A. S.; ONOFRE, E. M. C. (Orgs). O espaço da prisão e suas práticas educativas: enfoques e perspectivas contemporâneas. São Carlos: EdUFSCar, 2011. p. 267-285.

PENNA, M. G. de O. O ofício de professor: ambigüidades do exercício da docência por monitores-presos. 2003. Dissertação (Mestrado em Educação) - Pontifícia Universidade Católica, São Paulo, 2003. 
PÉREZ - GÓMEZ, A. I. La encrucijada de culturas. Investigación en la escuela. n. 26, p 7-24, 1995.

RANGEL, H. (Coord.). Mapa Regional latinoamericano sobre educación en prisiones. Notas para el análisis de la situación y la problemática regional. Centre International d'études pédagogiques (CIEP), 2009.

REGO, T. C.; MELLO, G. N. de. Formação de professores na América Latina e Caribe: a busca por inovação e eficiência. In: Conferência Internacional Desempenho dos Professores na América Latina: tempo de novas prioridades. Brasília, DF, 2002.

SCARFÓ, F. J. El derecho a la educación en las cárceles como garantia de la educación en derechos humanos (EDH). Revista IIDH. v. 36, p. 291-324, 2002.

SERRADO JUNIOR, J. V. Políticas públicas educacionais no âmbito do sistema penitenciário: aplicações e implicações no processo de (re)inserção social do apenado. 2009. Dissertação (Mestrado em Educação). Universidade Estadual Paulista, 2009.

SILVA, M. C. M. da. O primeiro ano de docência: o choque de realidade. In: ESTRELA, M.T. (Org.). Viver e construir a Profissão Docente. Porto: Porto Editora, 1997, p. 51-80.

SILVA, R. da. A eficácia sócio-pedagógica da pena de privação da liberdade. 2001. Tese (Doutorado em Educação). Faculdade de Educação, Universidade de São Paulo, São Paulo. 2001.

STRECK, D. R.; ADAMS, T.; MORETTI, C. Z. Pensamento pedagógico em nossa América: uma introdução. In: STRECK, D. R. (Org). Fontes da Pedagogia LatinoAmericana: uma antologia. Belo Horizonte: Autêntica, 2010. p. 19-35.

SYKES, G. M. The society of captives: a study of a maximum security prison. New Jersey: Princeton University Press, 1999.

VEENMAN, S. El proceso de llegar a ser professor: um análisis de la formación inicial. In: VILLA, A. (Coord.). Perspectivas y problemas de la función docente. Madrid, 1988, p. 39-68.

VIEIRA, E. L. G. Trabalho docente: de portas abertas para o cotidiano de uma escola prisional. 2008. Dissertação (Mestrado em Educação). Pontifícia Universidade Católica do Rio de Janeiro, Rio de Janeiro, 2008.

WHITE, R.T. The study of lives. New York: Dryden, 1989.

Recebido em fevereiro/2012

Aprovado em maio/2012 